\title{
Thermal fatigue assessment of components made with particulate polymer composites
}

\author{
C. Capela ${ }^{\text {a }}$, J.D. Costa ${ }^{\text {b }}$, F. Antunes ${ }^{\text {b }}$, J.M. Ferreira ${ }^{b, *}$ \\ ${ }^{a}$ Department of Mechanical Engineering, Instituto Politécnico de Leiria, Leiria, Portugal \\ ${ }^{\mathrm{b}}$ Department of Mechanical Engineering, University of Coimbra, Pinhal de Marrocos, 3030 Coimbra, Portugal
}

\begin{abstract}
Many appliance materials are made of PMMA/Si acrylic casting dispersion. In these situations, failure can occur by thermal fatigue induced by severe temperature variations such as alternating flows of cold and hot water. This paper is concerned with the numerical analysis of the thermal stresses in three composites with different volume fractions of filler and particle size. Their trade marks are Asterite, Amatis and Ultra-quartz. Cosmos/M finite element method software was used to study the influence of the cold and hot water temperatures as well as the time of interruption of water flow in the transition between hot and cold water on thermal stresses. Residual stresses were measured and superimposed to thermal stress in fatigue analysis. Typical defects in the corner of holes produced by drilling were predicted using experimental fatigue lives and $\mathrm{d} a / \mathrm{d} N$ curves. Based on predicted defects thermal fatigue assessment of commercially available sinks made with the three materials mentioned earlier was done by taking into account the influence of both cyclic thermal and static residual stresses induced by the manufacturing process.
\end{abstract}

(c) 2004 Elsevier Ltd. All rights reserved.

\section{Introduction}

The PMMA/Si acrylic casting dispersion is a composite used to substitute for many indoors household ceramics. Some examples are kitchen sinks, sanitary ware or sanitary furniture. In general, the addition of rigid particles to polymers increases the stiffness, reduces the thermal expan-

\footnotetext{
${ }^{*}$ Corresponding author. Tel.: +351 239790700; fax: +351 239790701.

E-mail address: martins.ferreira@dem.uc.pt (J.M. Ferreira).
}

sion, and produces an improvement in creep resistance and fracture toughness. In previous work of the authors $[1,2]$ these trends were confirmed for the materials under study in this paper. The effect of temperature on the mechanical properties has also been tested before. Young's modulus, static strength and fracture toughness were found to decrease with temperature. Also in a previous work $[3,4]$ a fatigue study with both constant and variable loading amplitude was performed. It was concluded that the fatigue strength of these composites is lower than the unfilled matrix, but the 
fatigue crack growth resistance is significantly higher relatively to the unfilled matrix. The increase of the particle size improves the fatigue crack growth resistance but reduces the fatigue strength, due to the increase of the initial defect size. The influence of temperature and stress ratio on the fatigue strength was also analysed and it was found that their increase produce a decrease of the fatigue strength. Despite the increase of the fracture toughness of these composites provided by the addition of silica particles, some failures had been observed in service in kitchen sinks manufactured with these materials. These fractures seem to be due to a thermal fatigue phenomenon originated by the alternated flows of cold and hot water.

This work is a complement of previous works $[1-4]$ and reports the results of a numerical analysis concerning the determination of thermal stresses induced by alternating flows of cold and hot water. Thermal stresses were determined and the influence of both cold and hot water temperatures were analysed. Also residual stresses were measured and integrated into the fatigue analysis. The main objective is to obtain the maximum values of the compression and tension stresses in order to assess the tolerance of defects concerning fatigue failure in thermal service conditions of sinks made with the materials mentioned above.

\section{Material properties and numerical procedure}

The materials studied were acrylic casting dispersions with different volume fractions and size of silica particles. Table 1 presents the composition for the three castings, whose trademarks are Asterite, Amatis and Ultra-quartz and also the mechanical properties of these materials obtained by the authors in a previous work [2] for temperatures ranging between 0 and $80^{\circ} \mathrm{C}$. Polynomial equations were fitted to the modulus data and used in strain-stress analysis. $\sigma_{\mathrm{UTS}}$ and $K_{\mathrm{c}}$ were obtained according the specifications of standards $[5,6]$, respectively.

Thermal parameters are necessary in the finite element analysis for the determination of thermal stress. They consist of thermal conductivity, spe- cific heat and the convective heat transfer coefficient at the surface in contact with water flow. They were previously experimentally obtained and are also indicated in Table 1.

Fig. 1 presents the geometry considered in the numerical analysis developed to calculate the thermal stresses. Only half of the sink was analysed to reduce the numerical effort. This implies the consideration of adequate thermal and mechanical symmetry conditions. The mechanical and thermal boundary conditions are presented in Fig. 1. The incidence of water on the sink was simulated considering a circular area with $100 \mathrm{~mm}$ of radius (with the centre displaced for $Y=60 \mathrm{~mm}$ ) over which heat flux by convection occurs (Fig. 1). Fig. 2 shows a schematic representation of the input water temperature changes with the time. The parameters considered were: $T_{\max }$ (hot water temperature value), $T_{\min }$ (cold water temperature value), $t_{\mathrm{i}}$ (time of water incidence) and $t_{\mathrm{s}}$ (time without water incidence). The periods with incidence of water were simulated considering the average convective heat transfer coefficient $h=175$, while a factor $h=0$ was considered on the periods without water (i.e., that no convection occurs).

This physical problem was modelled by the finite element method using COSMOS/M commercial package. A total number of 4501 quadratic isoparametric elements, with 20 nodes for each element, and a total of 25,181 nodes were considered. A detail of the finite element mesh can be seen in Fig. 3.

Residual stresses were evaluated by differential hole drilling technique [7], in spite some limitations of the method in [8], using strain gauges Vishay 031RE and 062RE for curved holes and plane surfaces, respectively.

\section{Results and discussion}

\subsection{Validation of numerical thermal stress analysis}

Thermal stresses were compared with experimental results to validate the numerical procedure. Fig. 4 shows numerical and experimental results for an Asterite sink obtained at the corner of the 
Table 1

Composition, thermal and mechanical properties of the materials

\begin{tabular}{|c|c|c|c|c|}
\hline \multirow[t]{2}{*}{ Material (trade name) } & \multirow[t]{2}{*}{ Temperature $\left({ }^{\circ} \mathrm{C}\right)$} & \multicolumn{3}{|l|}{ Material } \\
\hline & & Asterite & Amatis & Ultra-quartz \\
\hline PMMA (vol.\%) & - & 56 & 52 & 36 \\
\hline Silica (vol.\%) & - & 44 & 48 & 64 \\
\hline Particle size $(\mu \mathrm{m})$ & - & 10 & 350 & 590 \\
\hline Density $\left(\mathrm{gcm}^{-3}\right)$ & - & 1.69 & 1.74 & 1.92 \\
\hline$\sigma_{\mathrm{UTS}}(\mathrm{MPa})$ & 10 & 59 & 35.5 & 21 \\
\hline$\sigma_{\mathrm{UTS}}(\mathrm{MPa})$ & 20 & 65 & 37.6 & 22 \\
\hline$\sigma_{\mathrm{UTS}}(\mathrm{MPa})$ & 40 & 52 & 31.9 & 23.5 \\
\hline$\sigma_{\mathrm{UTS}}(\mathrm{MPa})$ & 60 & 40.4 & 24.9 & 17.8 \\
\hline$\sigma_{\text {UTS }}(\mathrm{MPa})$ & 80 & 18.5 & 18.8 & 16.8 \\
\hline Thermal conduct. $\left(\mathrm{W} /\left(\mathrm{m}^{\circ} \mathrm{C}\right)\right)$ & - & 0.47 & 0.49 & 0.59 \\
\hline$C_{\mathrm{p}}\left(\mathrm{JK}^{-1} \mathrm{~kg}^{-1}\right)$ (Specific heat) & $30-100$ & $3.9 T+885.5$ & $3.7 T+885.8$ & $3 T+807$ \\
\hline$E(\mathrm{MPa})$ (Young's mod.)* & $0-80$ & $-0.6324 T^{2}-5.236 T+9332.7$ & $-0.5648 T^{2}-15.929 T+8752.6$ & $-0.0344 T^{2}-85.288 T+15141$ \\
\hline 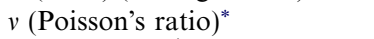 & $0-80$ & $0.0003935 T+0.24524$ & $0.0004074 T+0.2333$ & $0.000106 T+0.2205$ \\
\hline$K_{\mathrm{c}}\left(\mathrm{MPa} \mathrm{mm}^{1 / 2}\right)$ & 10 & 42.2 & 72.5 & 55.3 \\
\hline$K_{\mathrm{c}}\left(\mathrm{MPa} \mathrm{mm}^{1 / 2}\right)$ & 20 & 48 & 76.6 & 60 \\
\hline$K_{\mathrm{c}}\left(\mathrm{MPa} \mathrm{mm}^{1 / 2}\right)$ & 40 & 48.5 & 81.9 & 52.2 \\
\hline$K_{\mathrm{c}}\left(\mathrm{MPa} \mathrm{mm}^{1 / 2}\right)$ & 60 & 44.4 & 70.7 & 50.7 \\
\hline$K_{\mathrm{c}}\left(\mathrm{MPa} \mathrm{mm}^{1 / 2}\right)$ & 80 & - & 42.6 & 52.7 \\
\hline
\end{tabular}

UTS is the tensile strength, 

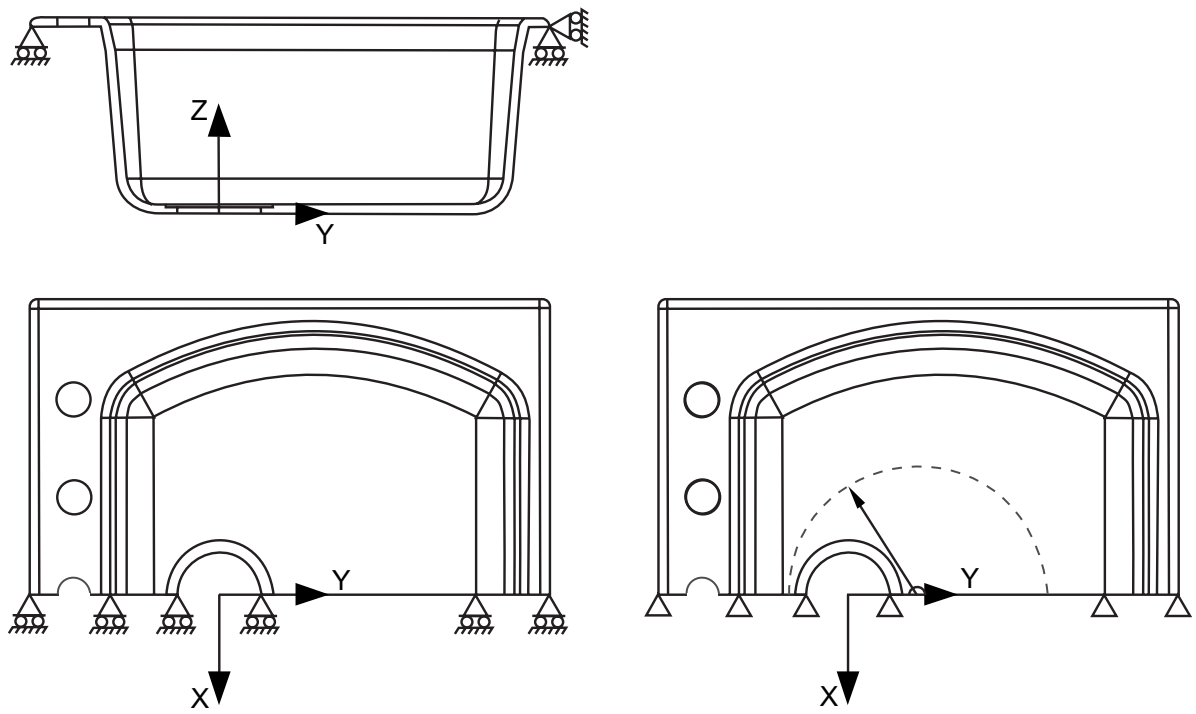

Fig. 1. Schematic sink design and boundary conditions.

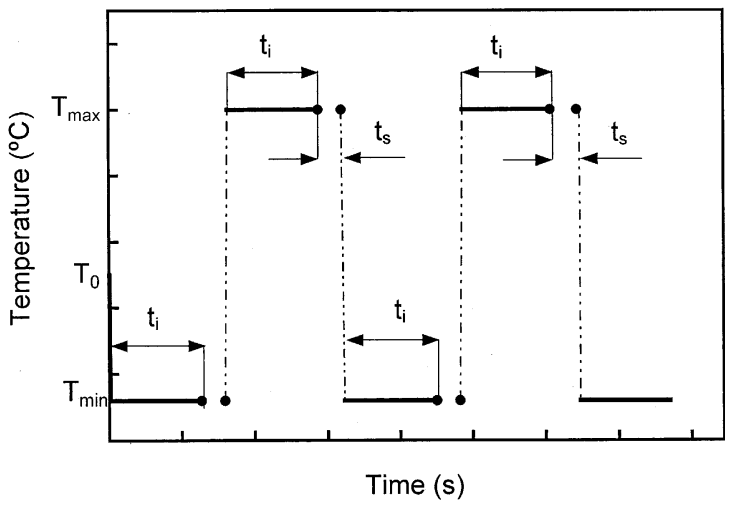

Fig. 2. Input water conditions.

waste hole. We plotted the tangent stress and surface temperature variations against the time during one thermal cycle. Experimental results were obtained using strain gauges placed in different points around the waste hole.

Compression stresses were obtained when the temperature was at maximum and tension stresses occur when the temperature is at minimum. Starting from room temperature $\left(20^{\circ} \mathrm{C}\right)$ a cold water flow of $5^{\circ} \mathrm{C}$ was applied originating tension stresses. While the temperature of the water is decreasing the tension stress increases. After this, there was a period that the cold water temperature was stabilized. Consequently a progressive reduction of the thermal gradient occurs in the material and the thermal stresses decrease. Due to the low thermal conductivity of this material, a great time is necessary for this to occur.

The explanation for the above trends is related with the contraction of the flow water incident region of the bottom sink, originated by cold water flow, which was partially restrained by the under levels of the thickness that had a higher temperature.

A further application of hot water leads to the inverse phenomenon, that is, the thermal expansion of the region of incidence of the water was partially restrained due to the lower temperature of the under levels of the thickness. Then, compression stresses occur and with higher values than the tension stresses.

A good agreement was obtained between numerical and experimental results, which validate subsequent analysis based only on numerical analysis. A mesh refinement considering six elements along the thickness (instead the three presented in Fig. 3) was also performed producing only negligible variations of the results. For reducing the computer time, the mesh presented in Fig. 3 was used in subsequent predictions. 


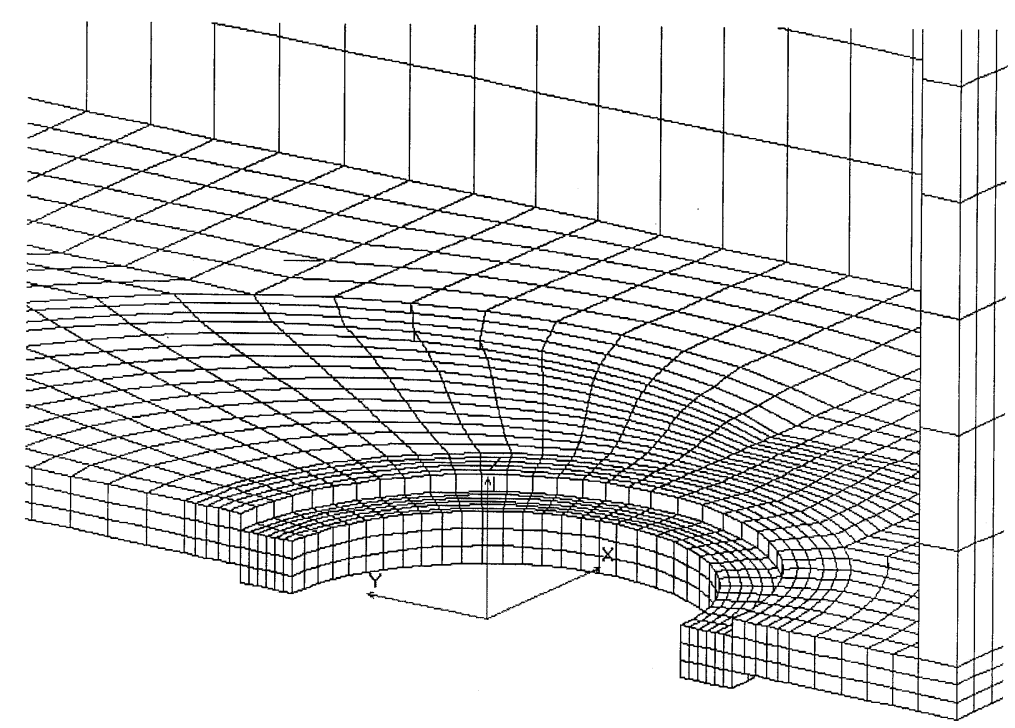

Fig. 3. Detail of finite element mesh.

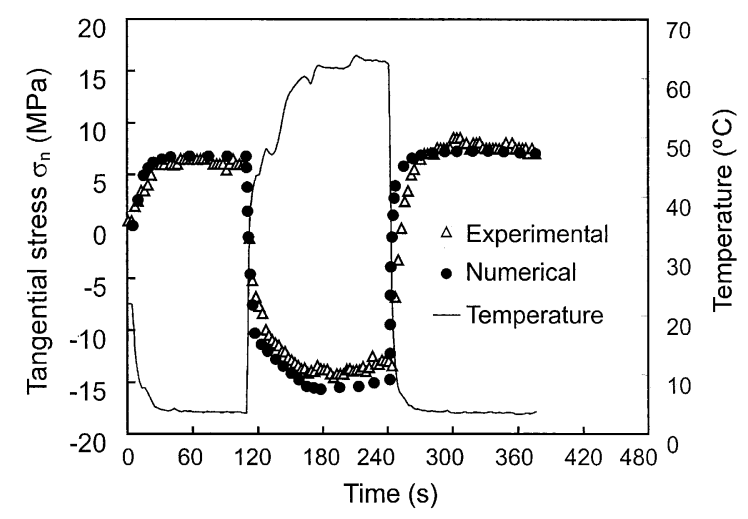

Fig. 4. Comparison between the numerical and experimental thermal stresses for a particular thermal cycle in Asterite manufactured skins.

\subsection{Numerical thermal stresses results}

Fig. 5 shows the variation at the tangent stress (stress along $X$ direction) at the corner of the hole for different values of $T_{\min }$ for Asterite sinks, using $t_{\mathrm{i}}=90 \mathrm{~s}$ and $t_{\mathrm{s}}=30 \mathrm{~s}$. Since $T_{\max }=90^{\circ} \mathrm{C}$ this produces an increase of temperature gradient between cold and hot water. An important increase was observed in maximum tensile stress from 2.4 to 6.9 $\mathrm{MPa}$ when $T_{\min }$ decrease from 20 to $5^{\circ} \mathrm{C}$.

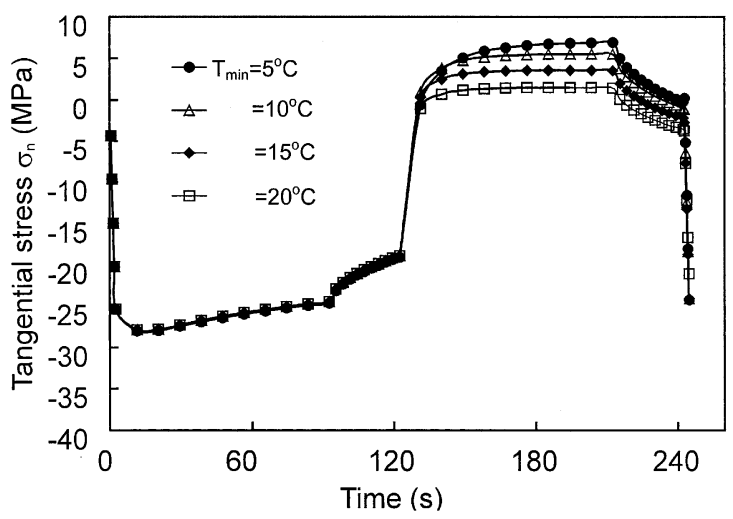

Fig. 5. Effect of $T_{\min }$ on numerical thermal stresses for Asterite sinks. $T_{\max }=90^{\circ} \mathrm{C} ; t_{\mathrm{i}}=90 \mathrm{~s}$ and $t_{\mathrm{s}}=30 \mathrm{~s}$.

Contrary to the important role of $T_{\min }$ on maximum tensile thermal stress a negligible effect of the time of water incidence, $t_{\mathrm{i}}$ and the time without water incidence, $t_{\mathrm{s}}$ was obtained as can be seen in the examples presented in Figs. 6 and 7, respectively. The important decrease of the maximum tensile thermal stress, close to drilled hole, with the increase of $T_{\min }$ can be observed in Fig. 8 for sinks manufactured with the three materials. Significant higher tensile stresses were obtained for Ultraquartz sinks being the lower values for the Asterite 


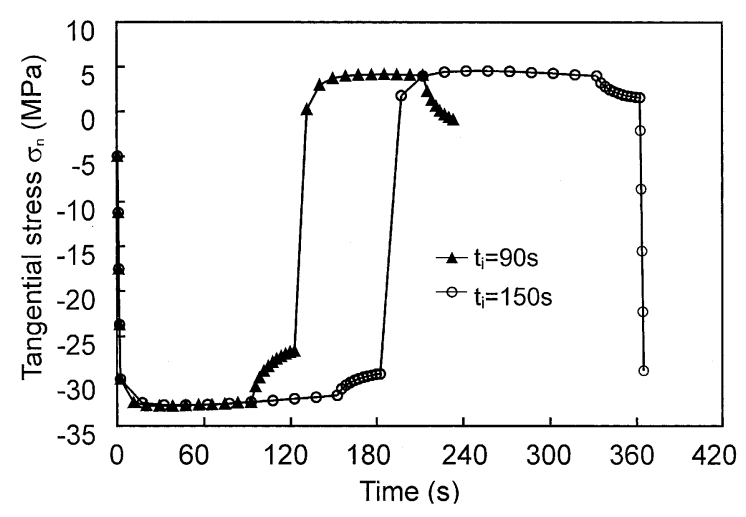

Fig. 6. Effect of $t_{\mathrm{i}}$ on numerical thermal stresses for Ultraquartz sinks. $T_{\max }=90^{\circ} \mathrm{C} ; T_{\min }=15^{\circ} \mathrm{C}$ and $t_{\mathrm{s}}=30 \mathrm{~s}$.

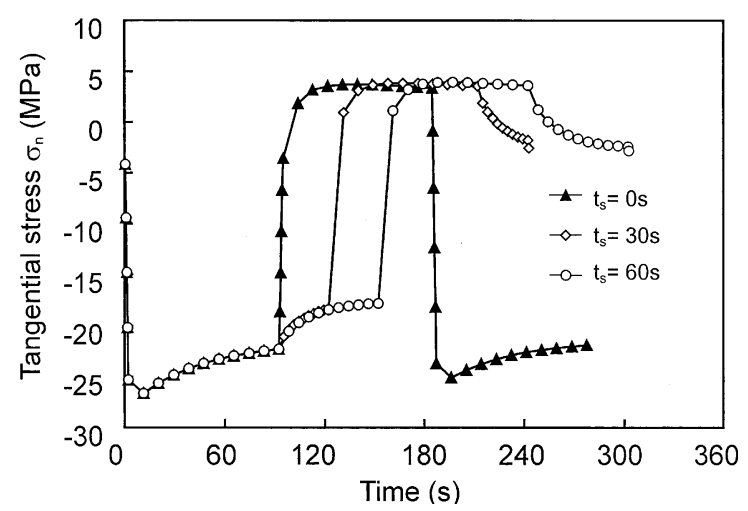

Fig. 7. Effect of $t_{\mathrm{s}}$ on numerical thermal stresses for Asterite sinks. $T_{\max }=90^{\circ} \mathrm{C} ; T_{\min }=15^{\circ} \mathrm{C}$ and $t_{\mathrm{i}}=90 \mathrm{~s}$.

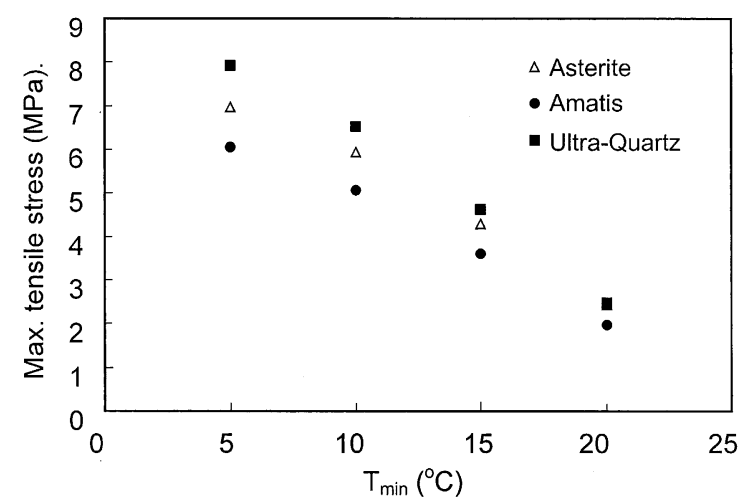

Fig. 8. Effect of $T_{\min }$ on numerical maximum tensile thermal stress. $T_{\max }=90^{\circ} \mathrm{C} ; t_{\mathrm{i}}=90 \mathrm{~s}$ and $t_{\mathrm{s}}=30 \mathrm{~s}$. sinks. These differences reduce significantly with the increase of $T_{\min }$. On the other hand the maximum compressive stresses reach a nearly constant value as a consequence of the maximum water temperature, $T_{\max }$, remains constant at $90^{\circ} \mathrm{C}$.

\subsection{Fatigue life of holed specimens}

An objective of this step was to predict the typical flaw sizes occurring at the corner of the drilled holes. In order to predict that size, an experimental fatigue study was performed in plane specimens with a central hole in uniaxial tensile loading [4]. The initial flaw sizes were obtained superimposing the experimental lives with the predicting ones taking into account the mechanical stresses and residual stresses promoted by hole drilling and surface machining of the specimens, as described subsequently.

Fatigue life predictions were performed based on the fracture mechanical $\mathrm{d} a / \mathrm{d} N-\Delta S$ curves, proposed in [9]. In fatigue propagation analysis an initial semi-circular crack $\left(c_{0}, a_{0}\right)$ created in the initiation phase was assumed and the number of cycles required to promote the growth of the initial crack till the fracture $\left(N_{\mathrm{f}}\right)$ was calculated. Table 2 presents, for the three materials, the constants of the crack propagation curves in the form:

$\mathrm{d} a / \mathrm{d} N=B(\Delta S)^{m}$

where

$$
\begin{aligned}
& \Delta S=2 a_{11} \Delta K_{\mathrm{I}} K_{\mathrm{Im}} \\
& \Delta K=K_{\max }-K_{\min } \\
& K_{\mathrm{Im}}=\left(K_{\max }+K_{\min }\right) / 2 \\
& a_{11}=(1+v) /(1-2 v) / E
\end{aligned}
$$

Table 2

Paris law constants $(\mathrm{d} a / \mathrm{d} N=(\mathrm{mm} /$ cycle $) ; \Delta S=(\mathrm{N} / \mathrm{m}))$

\begin{tabular}{llll}
\hline Material & $R$ & $m$ & $B$ \\
\hline Asterite & -0.75 & 3.65 & $6.31 \times 10^{-11}$ \\
& 0 & 6.88 & $7.944 \times 10^{-18}$ \\
Amatis & -0.75 & 7.432 & $3.548 \times 10^{-16}$ \\
& 0 & 6.299 & $6.31 \times 10^{-18}$ \\
UQ & -0.75 & 5.98 & $5.012 \times 10^{-13}$ \\
& 0 & 6.05 & $1.23 \times 10^{-16}$ \\
\hline
\end{tabular}


being: $\Delta K$ the stress intensity range, $K_{\mathrm{Im}}$ the average $K$ value, $v$ the Poisson coefficient and $E$ the Young's modulus. Instead $\mathrm{d} a / \mathrm{d} N$ curves for $R=0$ and $R=-0.75$ are not closed. Table 2 presents the material constants for the two stress ratios.

Fig. 9a-c plots the maximum principal residual stresses induced in a drilling hole against the depth for specimens manufactured with the three materials. In the holed specimens the holes were obtained by drilling while the plane was machined therefore residual stresses were produced by the two manufacturing processes. Residual stresses were measured in the thickness direction (plane surface points) and in the normal direction to the hole surface (hole surface points). In the sinks there are residual stresses produced by hole drilling and also by the cast of the material which were also superimposed against depth, in the thickness direction (cast surface points). In all the materials high surface residual stresses were obtained together with the typical trend to dissipation with depth. Residual stresses were fitted considering as approach a linear variation with the depth to surface. Fatigue crack propagation was modelled taking into account the propagation of the two extreme points: the deepest point in the thickness direction $(a$ depth point) and the plane surface point ( $c$ length point), as indicated schematically in Fig. 10. The fatigue crack propagation in both directions were carried out assuming a constant residual stress induced by machining, considering not strictly the surface value, but the residual stress value reached at one short distance from surface (assumed to be $0.1 \mathrm{~mm}$ for Asterite and $0.2 \mathrm{~mm}$ for Amatis and Ultra-quartz specimens) which attempt to consider the global effect of the residual stress gradient and also the particle size.

Adding the static residual stresses with the ones due to cyclic mechanical loading $(R=-0.75)$ an effective stress cycle was obtained corresponding to amplification in stress ratio and in maximum stress relatively to applied mechanical stresses. In crack propagation simulation the following approach is assumed: for each step the stress ratio $R$ was evaluated and then the propagation parameters corresponding to $R$ value ( $m$ and $B$ were available only for $R=0$ or $R=-0.75$ ) closer to
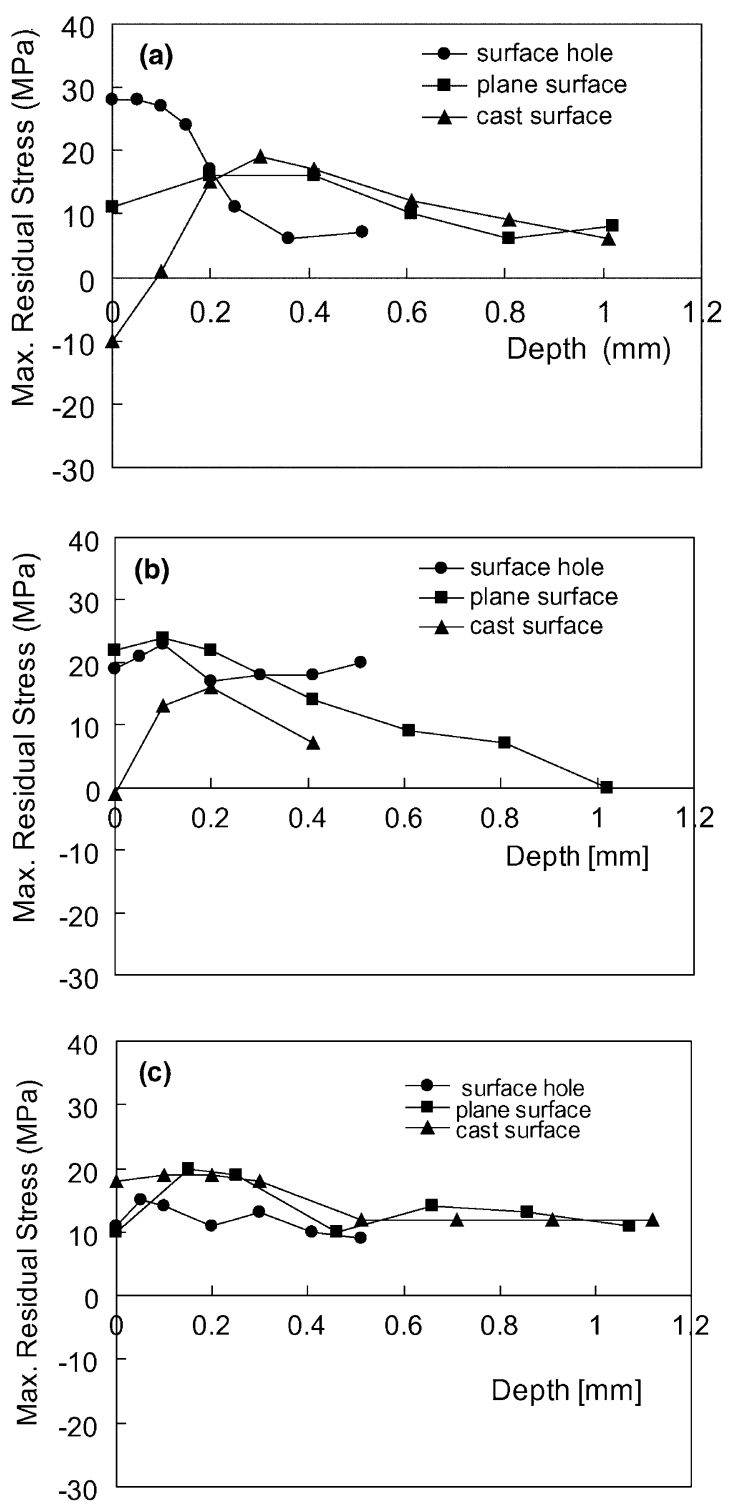

Fig. 9. Maximum principal residual stresses against the depth for surface hole drilled specimens, surface plate drilled and cast sinks. (a) Asterite, (b) Amatis, (c) Ultra-quartz.

the calculated values were used. The error induced by this approach, in the majority of the cases was not significant, once the evaluated effective stress ratio was much deflected from zero.

A previous $K$ solution obtained to study the fatigue crack propagation of symmetrical corner cracks on the central hole specimen [3] was used. 


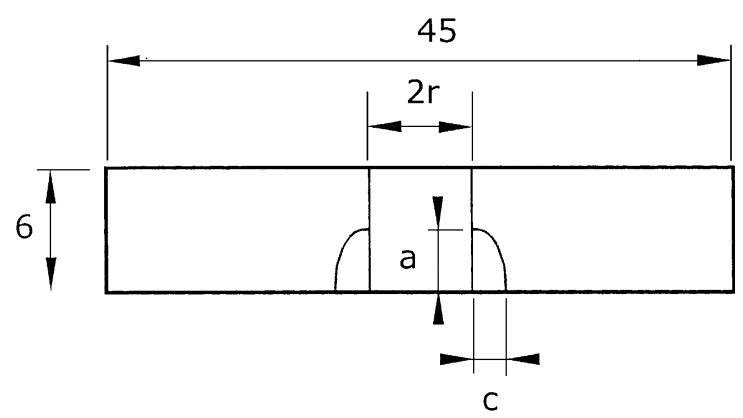

Fig. 10. Schematic view of the corner crack in drilled hole.

Crack length $a$ is measured in thickness direction and crack depth $c$ is measured as the distance to hole surface (Fig. 10). Two polynomial functions were obtained by regression from the numerical values of $K$ at the deepest and the surface point of a corner crack:

$$
\begin{aligned}
Y_{c}= & 1.871+1.063 x_{2}-0.884 x_{2}^{2}+0.179 x_{2}^{3} \\
& -12.927 x_{1}+13.954 x_{2} x_{1}-7.22 x_{2}^{2} x_{1} \\
& +1.486 x_{2}^{3} x_{1}+47.697 x_{1}^{2}-72.579 x_{2} x_{1}^{2} \\
& +43.773 x_{2}^{2} x_{1}^{2}+9.408 x_{2}^{3} x_{1}^{2}+69.24 x_{1}^{3} \\
& +123.298 x_{2} x_{1}^{3}-79.475 x_{2}^{2} x_{1}^{3} \\
& +17.389 x_{2}^{3} x_{1}^{3}+37.433 x_{1}^{4}-72.051 x_{2} x_{1}^{4} \\
& +47.494 x_{2}^{2} x_{1}^{4}-10.339 x_{2}^{3} x_{1}^{4}
\end{aligned}
$$

where $Y_{\mathrm{c}}=K_{\mathrm{c}} /\left(\sigma \cdot(\pi \cdot a)^{1 / 2}\right), \quad x_{1}=a / t, \quad x_{2}=a / c$ and $\sigma$ is the remote nominal stress. For the corner point at the hole (crack length $a$ ):

$$
\begin{aligned}
Y_{a}= & 3.227-3.075 x_{1}+5.613 x_{1}^{2}-2.519 x_{1}^{3} \\
& -1.15 x_{2}+2.446 x_{1} x_{2}-5.845 x_{1}^{2} x_{2} \\
& +3.103 x_{1}^{3} x_{2}+0.161 x_{2}^{2}-0.514 x_{1} x_{2}^{2} \\
& +1.508 x_{1}^{2} x_{2}^{2}-0.886 x_{1}^{3} x_{2}^{2}
\end{aligned}
$$

where $Y_{a}=K_{a} /\left(\sigma \cdot(\pi \cdot a)^{1 / 2}\right)$.

The remote nominal stress $\sigma$ is related with the net nominal stress in cross hole section $\sigma_{n}$ by

$\sigma=\sigma_{n}(w-d) / w$

where $w$ is the specimen width and $d$ the hole diameter.

Fig. 11a-c plots the predicted lives against the flaw size for specimens of the three materials for
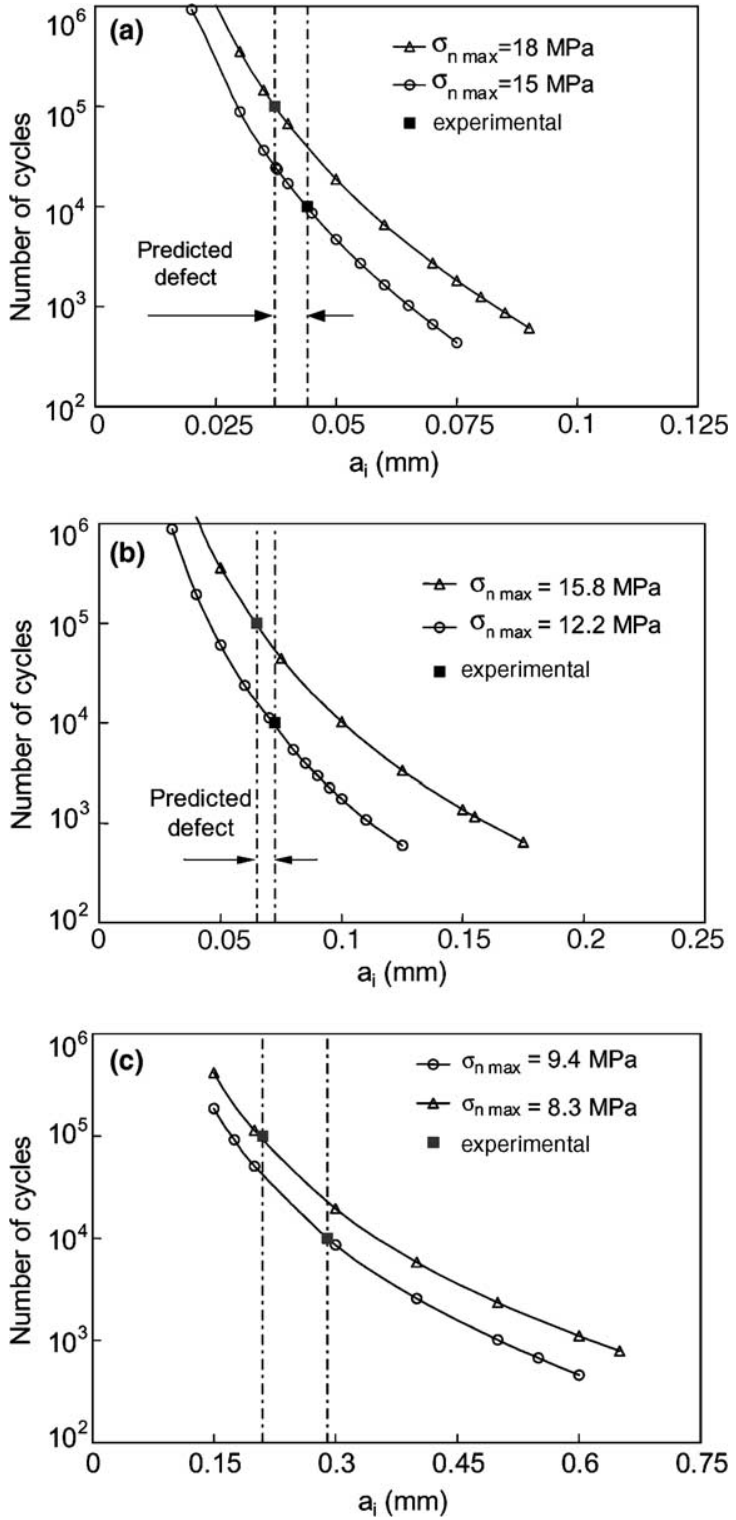

Fig. 11. Predicted lives against the initial flaw size. (a) Asterite specimens, (b) Amatis specimens, (c) Ultra-quartz specimens.

two high maximum stress levels which promotes experimental lives of $10^{4}$ and $10^{5}$ cycles, respectively, and then must provide short crack initiation phases. A point corresponding to the experimental life for each maximum stress level and a stress ratio $R=-0.75$ [4] was superimposed. Assuming that only fatigue crack propagation occurs the predicted propagation life and experimental one must 
be coincident and therefore a reference flaw size was predicted. The values obtained were: $0.037-$ $0.044 \mathrm{~mm}$ for Asterite, $0.065-0.073 \mathrm{~mm}$ for Amatis and $0.21-0.29 \mathrm{~mm}$ for Ultra-quartz. These values are significantly lower than those calculated previously without considering the residual stress effect [3], and corresponding with a particle size (not necessary the nominal particles size indicated in Table 1 , once the materials include particles with lesser sizes), except for the Asterite with a very fine particle size and where the defects produced by drilling must involve various particles, which seems to be a consistent prediction for carefully drilled laboratory specimens.

\subsection{Thermal fatigue analysis of sinks}

A thermal fatigue assessment of sinks manufactured with these materials containing drilled holes for water flow was now carried out taking in account the residual stresses induced as by drilling hole as by casting process during the manufacture of the sinks. Residual stresses were added with the numerical thermal stresses obtained previously. Residual stresses were considered as static loads and the thermal stresses as dynamic ones. Residual stresses induced by cast process were considered to predict the propagation in $c$ direction and those promoted by hole drilling along the thickness direction. As indicated before, residual stresses induced by the casting process are also presented in Fig. 9a-c and shows enormous variation near the surface depending of the particle size. For low particle size material (Asterite) residual stresses change from compressive values at the surface to high tensile values immediately at points near the surface. For greater particle size the values are always highly positive and for the intermediate particle size very low values were obtained at the surface being highly positive stresses observed immediately at the inner points. Consequently, an approach analysis was performed considering the residual stresses induced by the hole drilling equal to that used in the holed specimens and assuming for the residual stresses induced by cast process the values of $10 \mathrm{MPa}, 15 \mathrm{MPa}$ and $20 \mathrm{MPa}$.

The maximum and minimum thermal stresses were evaluated at bottom surface points and at
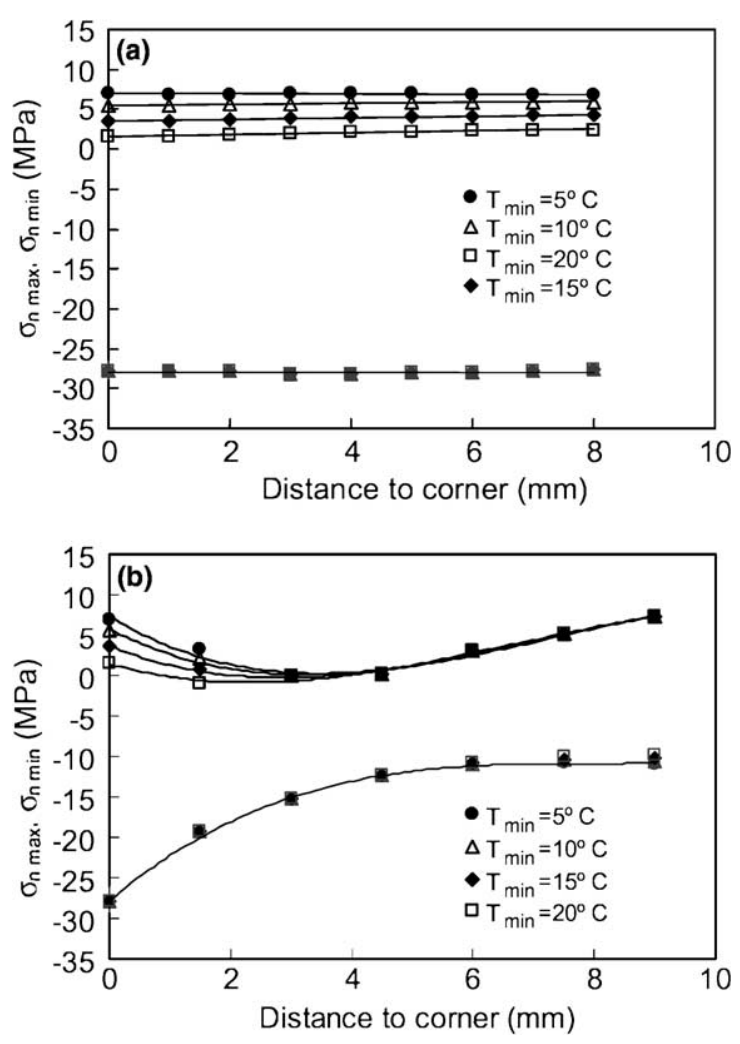

Fig. 12. Numerical thermal stress in Asterite sinks for: $T_{\max }=90^{\circ} \mathrm{C} ; t_{\mathrm{i}}=90 \mathrm{~s}$ and $t_{\mathrm{s}}=30 \mathrm{~s}$. (a) Thickness direction, (b) radial direction.

the hole surface. Fig. 12 plots an example of these calculations (for the higher stressed zone), for the case of Asterite sinks and: $T_{\max }=90^{\circ} \mathrm{C} ; t_{\mathrm{i}}=90 \mathrm{~s}$ and $t_{\mathrm{s}}=30 \mathrm{~s}$. From this figure it can be confirmed the negligible effect of $T_{\min }$ on compressive stresses, the important effect of $T_{\min }$ on tensile stresses, the negligible variation of tangent stress at the drilled hole surface (Fig. 12a) and an important tangent stress variation at the plane drilled surface in the corner region (Fig. 12b).

The crack propagation simulation was similar to that carried out for machined specimens. A $K$ solution obtained in [10] for corner cracks growing from a hole in a plate subjected to uniaxial tension was used, considering a hole diameter of $90 \mathrm{~mm}$ and a plate width of $350 \mathrm{~mm}$. Refer also to the work in [11] where the growth of the corner cracks has been analysed by using the strain energy density criterion. 
Fig. 13a-c presents the predicted lives against the initial flaw size for different residual stresses induced by cast process $T_{\min }$ (cold water temperature) for sinks manufactured in the different three materials. The service conditions $\left(T_{\max }=90^{\circ} \mathrm{C}\right.$;
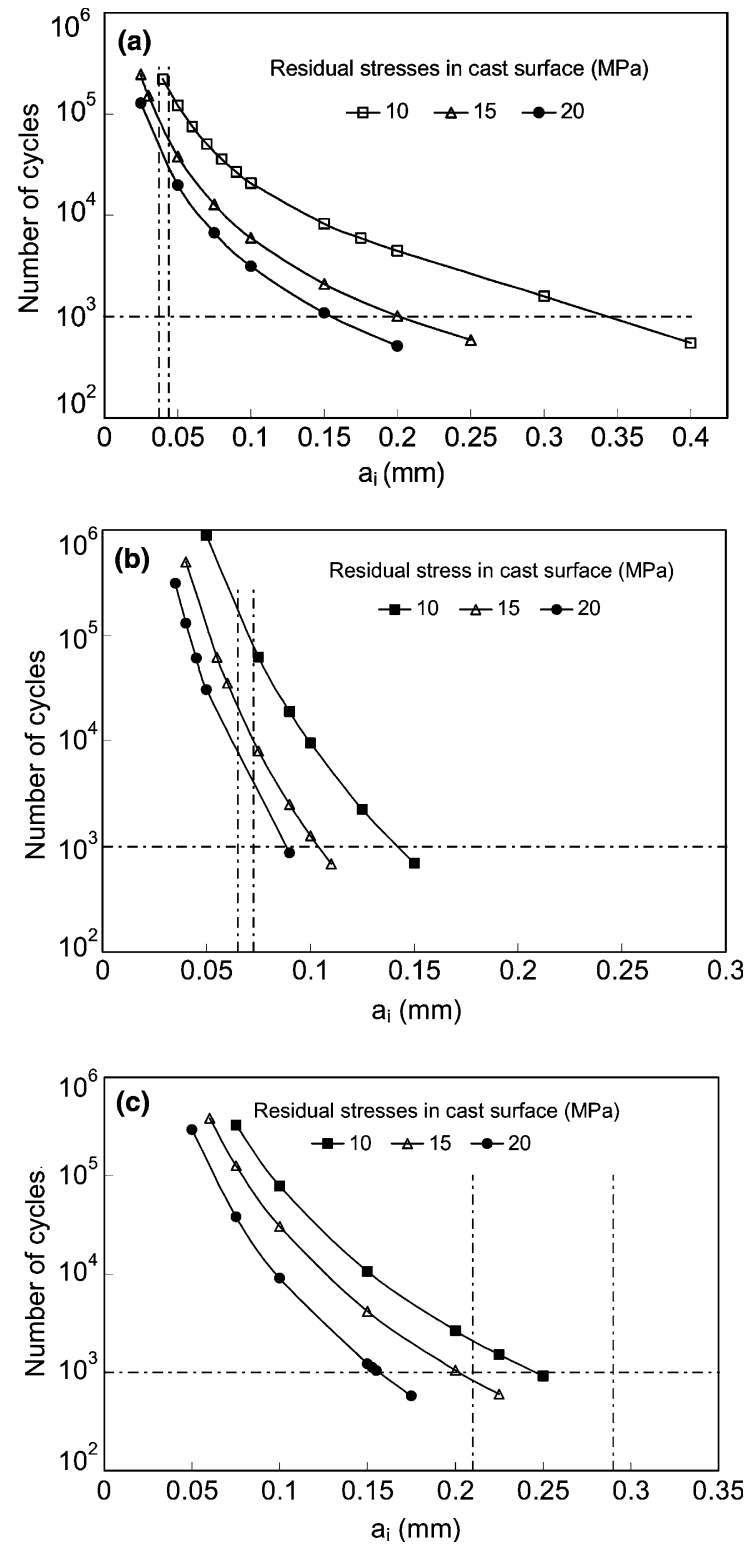

Fig. 13. Predicted lives against the initial flaw size for different residual stresses induced by cast process. $T_{\min }=15^{\circ} \mathrm{C}$; $T_{\max }=90^{\circ} \mathrm{C} ; t_{\mathrm{i}}=90 \mathrm{~s}$ and $t_{\mathrm{s}}=30 \mathrm{~s}$. (a) Asterite sinks, (b) Amatis sinks, (c) Ultra-quartz sinks.
$T_{\min }=15^{\circ} \mathrm{C} ; t_{\mathrm{i}}=90 \mathrm{~s}$ and $t_{\mathrm{s}}=30 \mathrm{~s}$ ) were defined according with European standard, prEN 13310 [12]. A reference line of 1000 thermal cycles corresponding to the minimum tolerable life according this standard was plotted. In spite of some unsuitable of the $K$ solution used concerning real geometry and an obvious doubt related with effective residual stresses, Fig. 13 shows a significant effect of residual stresses induced by cast process on tolerable defect in the corner of the hole. The three materials present similar tolerance to the machining defects. However, for components or specimens carefully machined the expected defects will increase with particle size. Superimposing in Fig. 13 the expected defects induced by drilling (vertical band lines) obtained previously it was taken evident that the failure is only expected in bigger particle size material sinks for a reference fatigue life of 1000 thermal cycles in severe service conditions and if high residual stresses were produced by cast process.

\section{Conclusions}

A thermal stress analysis for kitchen sinks manufactured in particulate composites was performed. The accuracy of numerical thermal stresses was evaluated for sinks subjected to alternate cycle flows of cold and hot water. An important decrease of maximum tensile stresses with the increase of cold water temperature and negligible effect of the time of water incidence and time of water flow interruption were found.

The flaw size produced in specimens by hole drilling was predicted using a fatigue crack propagation approach based on fracture mechanics considering the effects of external loading and residual stresses induced by drilling. The values obtained are close to the particle size, except for the Asterite which has a very fine particle size and where the defects produced by drilling seems to involve several particles.

Sinks manufactured with the three particle size materials also present similar fatigue tolerance to the machining effects. However, taking into account the higher expected defect sizes induced by drilling, failure can occur in bigger particle size material sinks for a reference fatigue life of 1000 
thermal cycles in severe service conditions and if high residual stresses were produced by the cast process.

\section{Acknowledgments}

The authors wish to thank the "SanitanaFábrica de Sanitários de Anadia, S.A." company for providing the material used in the tests and Professors M. Dias and P. Nobre of Coimbra University for their help in residual stress determination.

\section{References}

[1] J.M. Ferreira, J.D. Costa, C. Capela, Fracture assessment of PMMA/Si kitchen sinks made from acrylic casting dispersion, Theor. Appl. Fract. Mech. 26 (1997) 105-116.

[2] C. Capela, J.M. Ferreira, J.D. Costa, Fractura de compósitos poliméricos reforçados compartículas de sílica, Proc. Conf. CIDIM'99, Santiago do Chile, (1999).

[3] F. Antunes, J.M. Ferreira, J.D. Costa, C. Capela, Fatigue life predictions in polymer particle composites, Int. J. Fatigue 24 (2002) 1095-1105.
[4] J.D. Costa, J.M. Ferreira, C. Capela, Fatigue Behaviour of PMMA/silica Acrylic Casting Dispersions, Mater. Sci. Technol. 17 (12) (2001) 1657-1663.

[5] American Society for Testing and Materials, Standard Test for Tensile Properties of Plastics, Annual Book of ASTM, Part 35, ASTM D638, 1980.

[6] EGF Task Group on Polymers and Composites, A Linear Elastic Fracture Mechanics (LEFM) Standard for determining $K_{\mathrm{c}}$ and $G_{\mathrm{c}}$ for Plastics-Testing protocol for $K_{\mathrm{c}} / G_{\mathrm{c}}$ Standard, May 1988.

[7] American Society for Testing and Materials, Determining Residual Stresses by the Hole-drilling Strain-gage Method ASTM D 1934-84, 1984.

[8] A. Turnbull, A.S. Maxwell, S. Pillai, Residual Stress in Polymers-Evaluation of Measurement Techniques, J. Mater. Sci. 34 (1999) 451-459.

[9] G.C. Sih, Mechanics of Crack Initiation and Propagation, Kluwer Academic Publisher, Boston, 1991.

[10] J.C. Newman Jr., I.S. Raju, Stress-intensity factor equations for cracks in three-dimensional finite bodies subjected to tension and bending loads, in: S.N. Atluri (Ed.), Computational Methods in the Mechanics of Fracture, Elsevier Science Publishers, 1986, pp. 311-334.

[11] G.C. Sih, C.T. Li, Initiation and growth characterization of corner cracks near circular hole, J. Theor. Appl. Fract. Mech. 13 (1) (1990) 69-80.

[12] European Standard, Kitchen Sinks-Functional Requirements and Test Methods, Draft prEN 13310 (1998). 